\title{
Turbulent spark-jet ignition in SI gas fuelled engine
}

\author{
Ireneusz Pielecha ${ }^{1, *}$, Wojciech Bueschke ${ }^{1}$, Wojciech Cieślik $^{1}$, and Maciej Skowron ${ }^{1}$ \\ ${ }^{1}$ Poznan University of Technology, Faculty of Machines and Transport, ul. Piotrowo 3, 60-965 Poznan, Poland
}

\begin{abstract}
The article contains a thermodynamic analysis of a new combustion system that allows the combustion of stratified gas mixtures with mean air excess coefficient in the range 1.4-1.8. Spark ignition was used in the pre-chamber that has been mounted in the engine cylinder head and contained a rich mixture out of which a turbulent flow of ignited mixture is ejected. It allows spark-jet ignition and the turbulent combustion of the lean mixture in the main combustion chamber. This resulted in a two-stage combustion system for lean mixtures. The experimental study has been conducted using a single-cylinder test engine with a geometric compression ratio $\varepsilon=15.5$ adapted for natural gas supply. The tests were performed at engine speed $n=2000 \mathrm{rpm}$ under stationary engine load when the engine operating parameters and toxic compounds emissions have been recorded. Analysis of the results allowed to conclude that the evaluated combustion system offers large flexibility in the initiation of charge ignition through an appropriate control of the fuel quantities supplied into the pre-chamber and into the main combustion chamber. The research concluded with determining the charge ignition criterion for a suitably divided total fuel dose fed to the cylinder.
\end{abstract}

\section{Introduction}

Urbanization and industrialization have led to a sharp increase in transportation demand worldwide. World consumption of energy has reached 12,730 Mtoe, of which $23 \%$ is produced using natural gas, which proves its spread and increased popularity as vehicle fuel. There are currently more than 18 million CNG-powered vehicles in the world, of which around 93\% are light duty vehicles and trucks. Natural gas can be refueled at over 26,600 stations around the world [1].

Combustion engines powered by natural gas, so called: mono-fuel engines, are equipped with combustion systems that allow for the formation of mainly homogeneous fuel mixtures, often of a composition close to stoichiometric. However, wide flammability range of $4.3-15.2 \%(\mathrm{v} / \mathrm{v})$, and high self-ignition temperature (above $540 \mathrm{deg}$. C) allow for the use of $\mathrm{CNG}$ in combustion systems using lean fuel mixtures.

The engine thermal efficiency is strongly dependent on the compression ratio $[2,3]$ and used fuel [4-6]. The high octane number of CNG (120-130) allows for compression ratio of up to 16 , without any fear of engine knocking [1]. The gas engines can use either direct or indirect fuel injection systems.

Natural gas combustion takes place differently than the combustion of gasoline or diesel fuel. Natural gas has a higher ignition delay compared to liquid fuels, due to its lower flame propagation speed. As a result, the power of the gas powered engine may be about $5-10 \%$ less than that of a liquid powered engine [7, 8]. The comparison of the parameters of main fuels used in combustion engines is presented in Table 1 .
Tahir et al. [9] by analyzing a SI engine powered with gas and petrol concluded, that the cylinder pressure in the gas engine was $18.5 \%$ lower than in the petrol powered engine, which was attributed to a $23 \%$ decrease in the heat output compared to the petrol engine. Such combustion conditions are due to the reduced volumetric efficiency of the engine when powered with natural gas while gas volume displaces air from combustion chamber.

Table 1. Comparison of main parameters of engine fuels [7].

\begin{tabular}{|l|c|c|c|}
\hline \multicolumn{1}{|c|}{ Properties } & CNG & Gasoline & Diesel \\
\hline Octane/cetane number & $120-130$ & $85-95$ & $45-55$ \\
\hline Molar mass [kg/mol] & 17.3 & 109 & 204 \\
\hline Stoichiometric $(\mathrm{A} / \mathrm{F})$ mass & 17.2 & 14.7 & 14.6 \\
\hline $\begin{array}{l}\text { Stoichiometric mixture } \\
\text { density }\left[\mathrm{kg} / \mathrm{m}^{3}\right]\end{array}$ & 1.25 & 1.42 & 1.46 \\
\hline LHV [MJ/kg] & 47.5 & 43.5 & 42.7 \\
\hline $\begin{array}{l}\text { LHV of stoichiometric } \\
\text { mixture [MJ/kg] }\end{array}$ & 2.62 & $2.85-2.75$ & \\
\hline $\begin{array}{l}\text { Combustion energy } \\
{\left[\mathrm{MJ} / \mathrm{m}^{3}\right]}\end{array}$ & 24.6 & 42.7 & 36 \\
\hline $\begin{array}{l}\text { Flammability limit in air } \\
{[\text { vol\% in air] }}\end{array}$ & $4.3-15.2$ & $1.4-7.6$ & $1-6$ \\
\hline $\begin{array}{l}\text { Flame propagation speed } \\
{[\mathrm{m} / \mathrm{s}]}\end{array}$ & 0.41 & 0.5 & - \\
\hline Adiabatic flame temp. $\left[{ }^{\circ} \mathrm{C}\right]$ & 1890 & 2150 & 2054 \\
\hline Auto-ignition temp. $\left[{ }^{\circ} \mathrm{C}\right]$ & 540 & 258 & 316 \\
\hline Wobbe Index [MJ $/ \mathrm{m}^{3}$ ] & $51-58$ & - & - \\
\hline
\end{tabular}

*Corresponding author: ireneusz.pielecha@put.poznan.pl 
The use of CNG PFI engine allows for about 30\% decreased torque at low engine speeds relative to the SI DI engine [10]. It has been found, however, that the use of the CNG DI system and the optimization of the ignition angle can compensate for torque losses of over $60 \%$ at low engine speeds.

Choi et al. [11], by analyzing direct gas injection into the combustion chamber using the so-called homogeneity index, has shown that injection at higher fuel pressure allows for greater mixture homogeneity. Starting fuel injection at $180 \mathrm{deg}$. TDC at the pressure of 0.6 and $1.4 \mathrm{MPa}$ allows the index value to increase from 0.86 to 0.9 at an angle of 40 degrees before TDC. It has also been found that extending the injection time at lower fuel pressure does not significantly affect the homogenization of the fuel dose. This is confirmed by IMEP studies at various fuel injection pressures. Changes of the observed values oscillate in the range of $\pm 0.02 \mathrm{MPa}$. The change in engine performance indicators for the direct gas injection engine relative to a petrol fuelled engine with MPI were reported in the research results of Kalam and Masjuki [12]. The CNG DI engine showed about 2 percentage points lower heat efficiency $(29.2 \%$ versus $32 \%)$ compared to the MPI engine. With regards to emissions of exhaust gas components, a $42 \%$ reduction in nitrogen oxide emissions was noted, with $\mathrm{HC}$ emissions increasing by $25 \%$.

Research performed by Hall et al. [13] on a turbocharged 3-cylinder engine with a displacement of $1.2 \mathrm{dm}^{3}$ and a compression ratio of 13.3 in RDE (Real Driving Emission) test showed an increase in $\mathrm{CNG}$ engine thermal efficiency of around $2-10 \%$ at maximum loads and high engine speed relative to the petrol engine (SI DI, $\varepsilon=11.3$ ). The maximum speeding-up of the centre of combustion $(\mathrm{CoC})$ was recorded within the maximum load range and an average crankshaft rotational speed, and ranged from 10 to 18 degrees. Large values result from the engine knock recorded for petrol supply case and the necessary ignition delay. Full engine optimization resulted in the specific fuel consumption being reduced to $200 \mathrm{~g} / \mathrm{kWh}$ for gas fuelled engine compared to the $240 \mathrm{~g} / \mathrm{kWh}$ during a conventional gasoline direct injection test.

Natural gas engines emit less carbon monoxide and hydrocarbons (non-methane) compared to conventional gasoline-powered SI engines [14]. It has been observed that in this case over $90 \%$ of the unburned hydrocarbons are methane, which is 20 times more potent as a greenhouse gas than carbon dioxide [10]. Early particle number studies (year 2000) [15] generated by gas combustion in a spark-ignition engine indicate the presence of particles below $50 \mathrm{~nm}$ regardless of the test conditions (steady-state or transient). Contemporary research (2015) by Alanen et al. [16] shows that the largest number of particles is in the size range of 2-5 nm. The number of particles in the size range over $23 \mathrm{~nm}$ is significantly smaller compared to the numbers of the smallest particle size.

Simultaneous use of indirect injection (into the intake manifold) and direct injection allows using prechamber. Combustion of lean fuel mixtures in such systems reduces the maximum combustion temperature as well as reducing the emission of nitrogen oxides. This trend is also supported by the lower flame temperatures when burning gas mixtures (see Tab. 1).

Tests of a prechamber system coupled to the main chamber intended for use in engines of PC or LDV vehicles was presented by Attard et al. [17]. In this injection system, both indirect gas injectors (into the intake manifold) and direct gas injectors (to the prechamber) were used. The use of a prechamber increased the range of the air excess coefficient $\lambda$ change (from 0.8 to 2.1 with gasoline/propane fuel mixture supply) with respect to combustion in a conventional fuel supply system (gasoline combustion $\lambda=0.7-1.4$ ).

A comparison of the conventional system and a TJI system (Turbulent Jet Ignition) indicated the possibility of using a higher air excess coefficient ( $\lambda=1.8$ for TJI), allowing for a simultaneous ignition delay (up to $5 \mathrm{deg}$.) and reduced the uneven engine operation $\mathrm{CoV}(\mathrm{IMEP})=$ $=1.0 \%$ for $\mathrm{TJI}$ system compared to $2.5 \%$ for conventional gasoline systems). The tests were carried out at a fixed peak cylinder pressure angle (of about $7 \mathrm{deg}$. on the crankshaft) and almost constant pressure increase after ignition (approx. $1.1 \mathrm{bar} / \mathrm{deg}$ ).

The commercial version of a combustion system utilizing an additional ignition chamber was also presented by Mahle in 2014 [18]. A portion of the gas was supplied to the prechamber, whose energy accounted for about $2 \%$ of the total fuel energy supplied. Combustion of a mixture of about stoichiometric composition took place in the prechamber.

Schumacher and Wensing [19] presented a prechamber system with a gas supply valve. A chamber the size of $1.57 \%$ of the entire combustion chamber was equipped with a spark plug M10 and a gas dosing valve. Application of the prechamber increased the engine performance by approximately $5 \%(\lambda=1.6, \mathrm{IMEP}=4.5$, $n=1500 \mathrm{rpm})$ when compared to a petrol engine $(\lambda=1)$.

Simulation studies of the liquid fuel injection process conducted with two prechambers were presented by Assanis et al [20]. It was found that the shape of the prechamber and of the piston influenced the velocity of fuel flow from the prechamber. A shape has been obtained, using simulation results, which allowed for complete fuel evaporation in the prechamber and no fuel gathering on the prechamber walls when flowing out of it. Simulation studies for the optimum prechamber shape concept indicated the possibility of burning a mixture with an air excess coefficient of $\lambda=3$ for liquid fuel.

The study of dual-fuel engines with a prechamber was published by Yousefi and Birouk [21]. The specificity of these tests consisted of injecting gas into the intake manifold and diesel fuel into the prechamber. The gas dose injected into the intake manifold was varied. It was found that increasing the share of gas delayed the combustion process, and when its share reaches over $60 \%$ it worsens the combustion process leading to misfire.

The use of lean mixtures in combination with prechambers has been researched by Ruter et al. in [22]. The prechamber in such systems represents $1-2 \%$ of the entire cylinder volume. The resulting exhaust gases 
formed in the prechamber leave it in the form of highenergy flame streams covering the main combustion chamber with multiple ignition points. The flame stream has a flash energy of 106 times that of the standard spark plug [22]. Additional simulation studies conducted in [23] demonstrate that the air/fuel ratio of $1 / 1.09$ achieves the lowest combustion time, with a $5.7 \%$ variation of the maximum combustion pressure. This confirms the hypothesis that the maximum laminar flame velocity in methane combustion is within the air excess coefficient range of $\lambda=1 / 1.05$ to $1 / 1.10$ [24].

Optimization of the HDV natural gas fuelled prechamber was discussed by Heuser et al. [25]. Changes in the chamber geometry allowed for combustion of fuel mixtures with $\lambda=2.1$, as well as significantly limiting the combustion duration (by 6 percent with respect to the main chamber). More advantageous distribution and orientation of the outlet channels from the prechamber allowed to reduce the influence of gases flowing from the main chamber, thus increasing the air excess coefficient in the prechamber.

Research conducted by Tanoue et al. [26] using prechamber in a single cycle machine indicates the occurrence of a characteristic pressure increase in the prechamber. The pressure increase rate in the prechamber is all the greater since the spark plug is located at a greater distance from the orifices allowing the flow of prechamber gases into the main combustion chamber. In addition, the authors identified engine knocking with intensity related to the number of injector holes used for the prechamber injection. It has been found that the knocking occurs when the injector has a single hole, and the knocking itself takes place in the prechamber fuel outflow area. Utilizing a fast Fourier transform FFT, knock detection was performed in the $5-35 \mathrm{kHz}$ range. The highest frequencies were found at $6.7 \mathrm{kHz}$ and $11.2 \mathrm{kHz}$. The maximum value of the combustion pressure change caused by the engine knocking was $0.82 \mathrm{MPa}$. The temperature value in the vicinity of this phenomenon was estimated to be at the level of $2400-2500 \mathrm{~K}$.

\section{Motivation}

The search for optimal combustion systems solutions leads to increased interest in natural gas as a fuel that can potentially replace both diesel fuel and gasoline. The authors of this article, using the gasoline burning systems [27, 28], diesel [29-32] and dual fuel systems [33], used a combustion system with a prechamber for the research and analysis of the gas supply system thermodynamic optimization of a $\mathrm{CNG}$ spark ignition engine.

The article analyzes the prechamber combustion system in terms of fuel dose ignition. Therefore, an important element of the research work carried out is the fuel dosage rate analysis injected into the prechamber as well as the main chamber. These two parameters describing stratification of the charge and relating to the engine performance indicators are the main research focus of this article.

\section{Methodology}

\subsection{Test stand}

Research into determining the flammability limits was carried out on a single-cylinder test engine adapted for natural gas supply (Fig. 1). The measuring stand was equipped with the necessary systems for the conditioning of the engine as well as carrying out the analysis of the combustion process and the emission of toxic exhaust components. The natural gas supply system contained additional damping volumes to ensure the correct indication on the gas flowmeter. For this reason, additional volumes were added before the injectors: a $2 \mathrm{dm}^{3}$ volume before the injector in the engine intake manifold and a $3.5 \mathrm{dm}^{3}$ volume in the direct injection system.

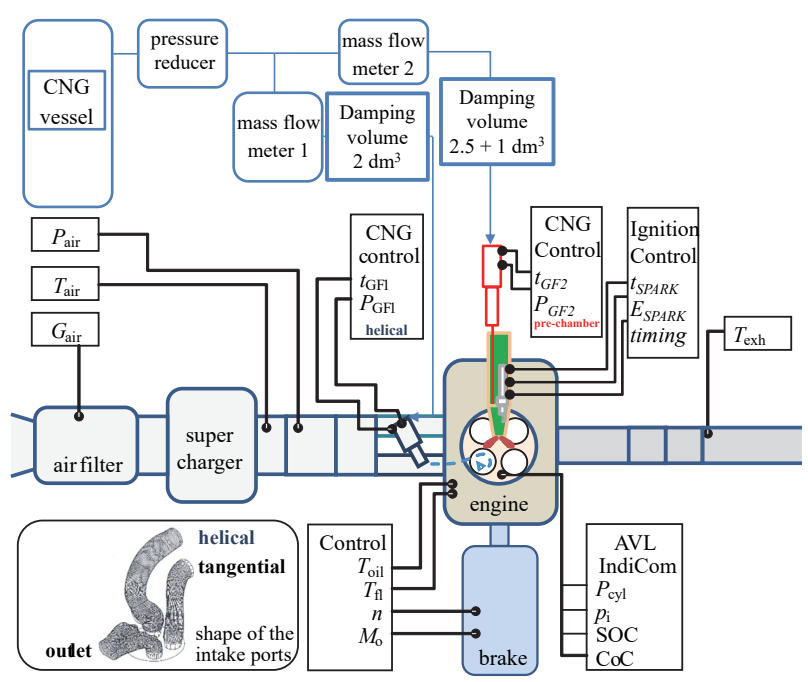

Fig. 1. Engine test stand for direct and indirect injection of natural gas.

The research engine base is an AVL 5804 structure, where the power supply, the piston design (combustion chamber) and the compression ratio have been modified. The standard compression ratio of the compression ignition engine (19.9) was lowered to 15.5 (Tab. 2).

Table 2. Test engine characteristic.

\begin{tabular}{|l|c|c|}
\hline \multicolumn{1}{|c|}{ Parameter } & Unit & Value \\
\hline Engine & - & 1-cylinder, 4-valve, SI \\
\hline Cylinder volume & $\mathrm{dm}^{3}$ & 0.5107 \\
\hline Bore x stroke & $\mathrm{mm}$ & $85 \times 90$ \\
\hline Compression ratio & - & 15.5 \\
\hline Fuel system & - & $\begin{array}{c}\text { Direct and indirect injection } \\
\text { (electromagnetic injectors) }\end{array}$ \\
\hline Air system & - & Supercharging \\
\hline
\end{tabular}

\subsection{Research equipment}

The engine test stand was equipped with the necessary measuring systems (engine dynamometer) and systems for recording fast processes (Table 3). Due to the use of 
two gas supply systems, the gas flow measurements were made using two separate flow meters designed for large and small flows. At the same time, apart from the pressure in the cylinder, electrical voltage on the injectors and the voltage in the primary circuit of the ignition coil were measured.

Table 3. Equipment used in research.

\begin{tabular}{|l|c|c|}
\hline \multicolumn{1}{|c|}{ Parameter } & Producer/name & Description \\
\hline Engine brake & $\begin{array}{c}\text { AVL AMK } \\
\text { DW13-170 }\end{array}$ & $-50-300 \mathrm{Nm}$ \\
\hline \multirow{2}{*}{ Air system } & $\begin{array}{c}\text { Sensycon } \\
\text { Sensyfolw }\end{array}$ & $0-720 \mathrm{~kg} / \mathrm{h}$ \\
\hline Fuel system & Emerson mCMFS & $0.1-2 \mathrm{~kg} / \mathrm{h}$ \\
\cline { 2 - 3 } Oil system & Bronkhorst 111B & $0.1-100 \mathrm{~g} / \mathrm{h}$ \\
\hline Water system & AVL 577 & $0-150 \mathrm{deg} \mathrm{C}$ \\
\hline $\begin{array}{l}\text { Fast-varying } \\
\text { processes } \\
2 \text { parameter }\end{array}$ & AVL IndiSmart & $0-150 \mathrm{deg} \mathrm{C}$ \\
\hline \multirow{2}{*}{ Emission } & AVL Concerto & Post-processing \\
\hline
\end{tabular}

Injection of the fuel dose into the prechamber and the inlet manifold occurred at $160 \mathrm{deg}$. before the piston TDC. The ignition advance was 15 degrees, but at the maximum fuel dose delivered to the cylinder, the ignition was delayed to 13 degrees to maintain the proper angle of incidence of the peak cylinder pressure. The gas pressure delivered to both injectors was 8 bar overpressure relative to the ambient pressure. The coil charging current was $5.5 \mathrm{~A}$.

\subsection{Research plan}

Flammability tests of the fuel mixture have been conducted on a wide range of variations in its composition, with differentiated values for the primary dose and the prechamber dose. The test conditions are shown in Table 4 . The range of test points was chosen in such a way as to obtain as low a dose of prechamber fuel injected as possible. The injection dose to the prechamber was limited by the minimum operating time (opening) of the injector mounted in the prechamber (a dose of $0.5 \mathrm{mg} / \mathrm{inj}$ was found to be the limit in this case).

Table 4. Test conditions.

\begin{tabular}{|c|c|c|c|}
\hline $\begin{array}{c}n \\
{[\mathrm{rpm}]}\end{array}$ & $\begin{array}{c}P \text { in } \\
{[\mathrm{bar}]}\end{array}$ & $\begin{array}{c}\text { qo_PC } \\
{[\mathrm{mg} / \mathrm{inj}]}\end{array}$ & qo_MC $[\mathrm{mg} / \mathrm{inj}]$ \\
\hline 2000 & 1.03 & $\begin{array}{c}0.5-3.0 \\
\text { variable }\end{array}$ & ca. $15 ;$ ca. $16 ;$ ca. $17.5 ;$ ca. 19 \\
\hline
\end{tabular}

The study was conducted at 37 measurement points (Fig. 2), maintaining a distribution of measurement points as uniform as possible, which allows for a wide range of load conditions. Fuel injected into the prechamber only serves as the ignition initiator and creates spark-jet ignition of the fuel mixture in the engine main combustion chamber. Therefore, the measurement points were selected so as to minimize its share in the total fuel dose. From the initial analysis of the dose injected into the prechamber, it appears (Fig. 3) that the maximum dose share of the prechamber injection relative to the total dose reaches values greater than $16 \%$ (for a small main injection dose) down to about $10 \%$ (for a large main dose). The minimum fuel dose share injected into the prechamber obtained in the tests was between $4 \%$ and $3.5 \%$. The greater the size of the main dose, the smaller the dose share of the gaseous fuel delivered into the prechamber.

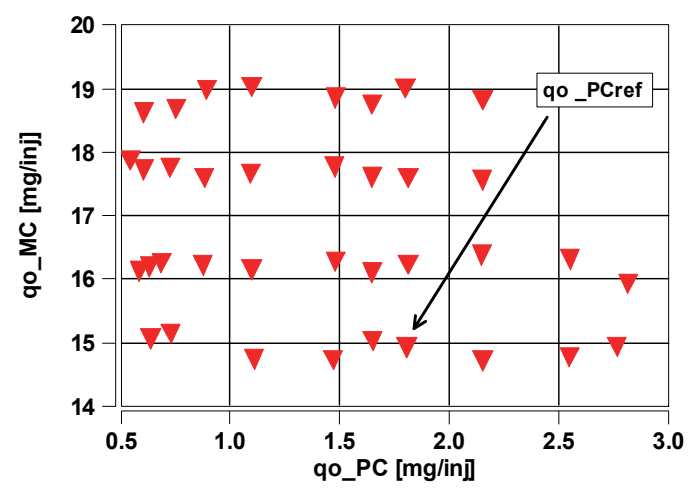

Fig. 2. Measurement points used to determine the fuel mixture flammability.

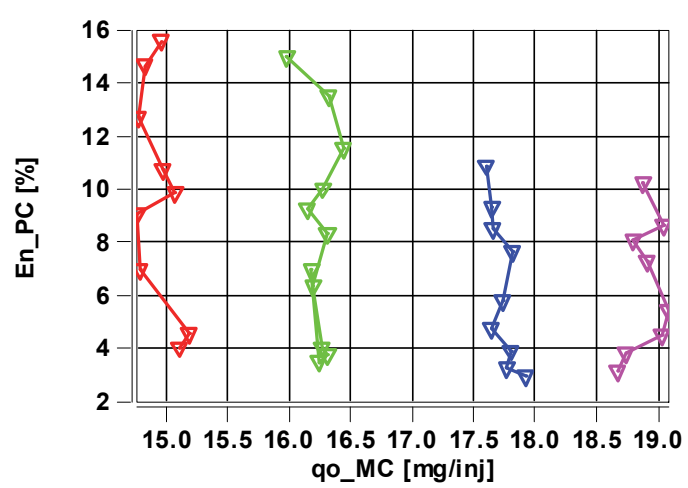

Fig. 3. Energy share of the prechamber dose with respect to the total fuel dose.

The main limitation of prechamber dose reduction was either a very irregular engine operation with a high proportion of misfires or the achievement of the lower fuel dose limit (around $0.5 \mathrm{mg} / \mathrm{inj}$ ). Research in such conditions has been carried out to determine the limits of the lean gaseous mixtures inflammability.

\section{Determining the fuel mixture inflammability limits}

The research plan presented in Section 3.3 and a variable signal analysis allowed to determine the Coefficient of Variation $(\mathrm{CoV})$ from IMEP, which is a measure of the engine operation uniformity, which determined the acceptable engine operating limits. It was assumed that the maximum value $5 \%$ of this coefficient determines the gas mixture ignition limits.

From the data shown in Fig. 4, it can be seen that the uneven engine operation is related to low fuel doses fed 


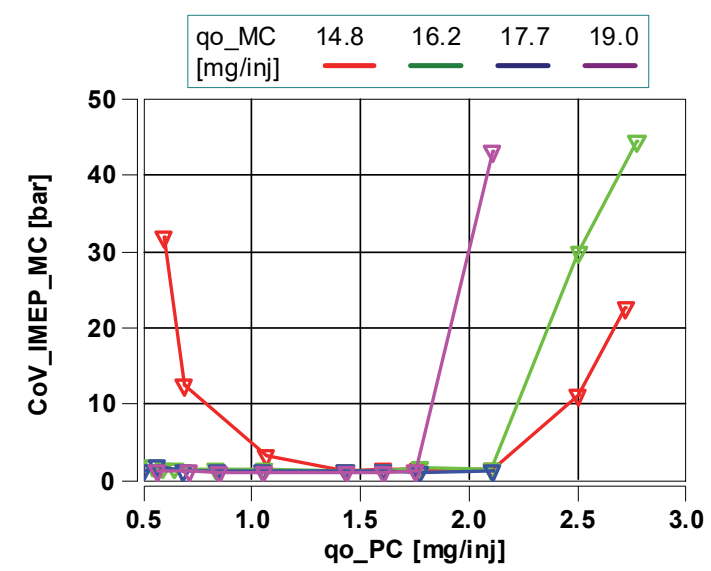

Fig. 4. Determining the relation between the IMEP coefficient of variation and the prechamber dose share with respect to the total fuel dose. to both the prechamber and the main combustion chamber. Increasing the main chamber dose (with a minimum dose injected into the prechamber) does not result in abnormal engine operation $(\mathrm{CoV}(\mathrm{IMEP})<3 \%)$. Very big prechamber doses (greater than $2 \mathrm{mg} / \mathrm{inj}$ ) cause the engine to run in an unstable way and the $\mathrm{CoV}$ (IMEP) indicator reaches large values.

Determining the inflammability limits of lean gas-air mixtures required a cylinder pressure analysis, which determined the maximum cylinder pressure values for each engine work cycle. Irregularity of the engine work cycles was determined using the maximum cylinder pressure - CoV(Pm_MC). The subsequent part of this article shows only a part of the study of the minimum (q_PCmin), reference (q_PCref) and maximum (q PCmax) prechamber fuel dose with the minimum fuel dose being injected into the main combustion chamber (Fig. 5).
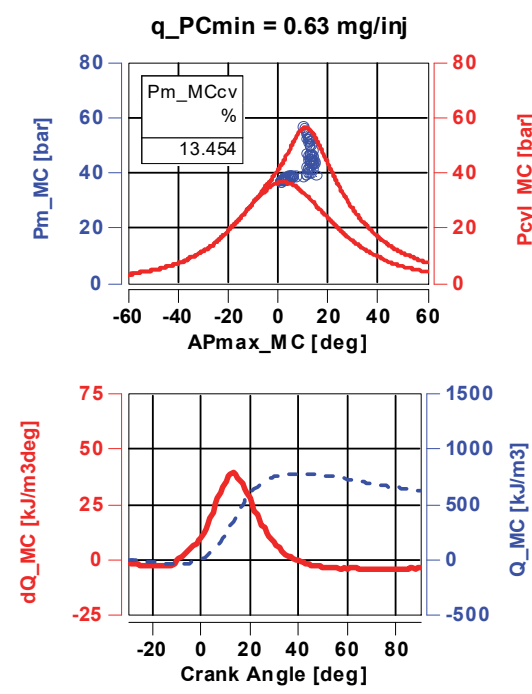
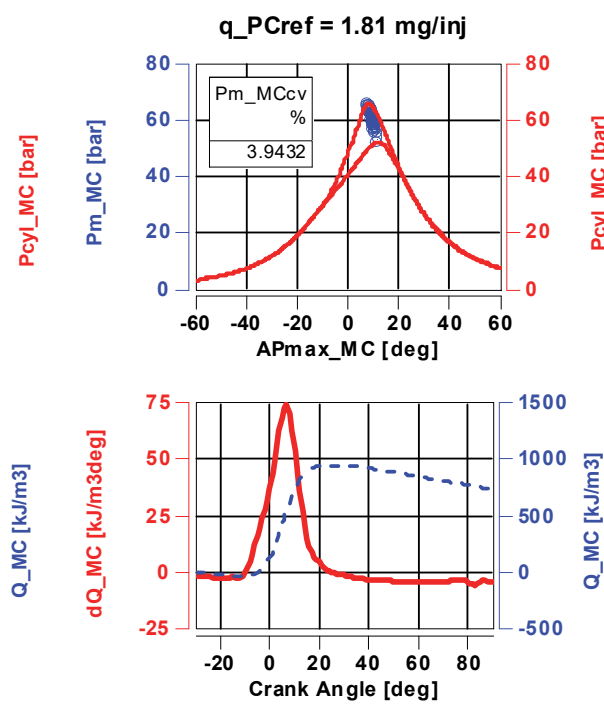
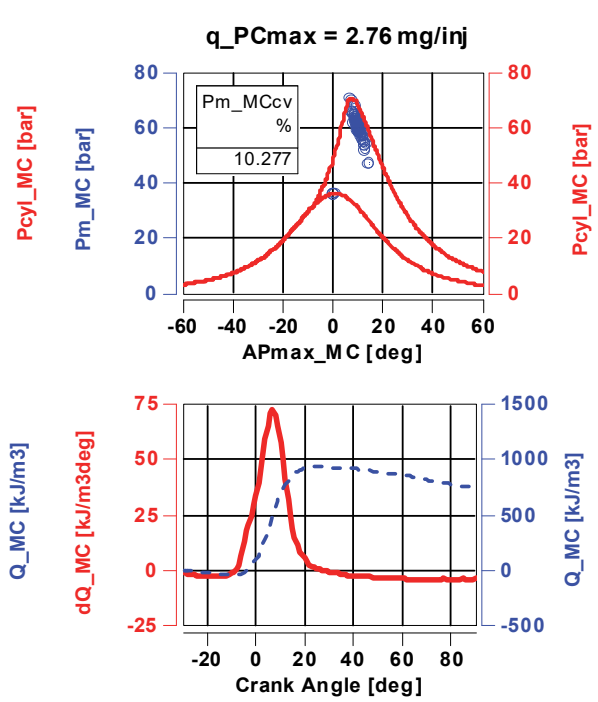

Fig. 5. Analysis of the combustion pressure and the heat release rate for small dose injection into the main combustion chamber (qo_MC $=15 \mathrm{mg}$ ).
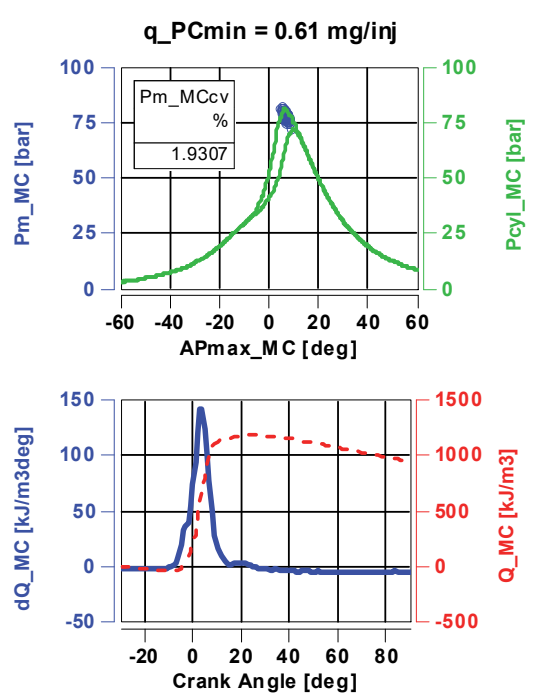

q_PCmin $=1.79 \mathrm{mg} / \mathrm{inj}$
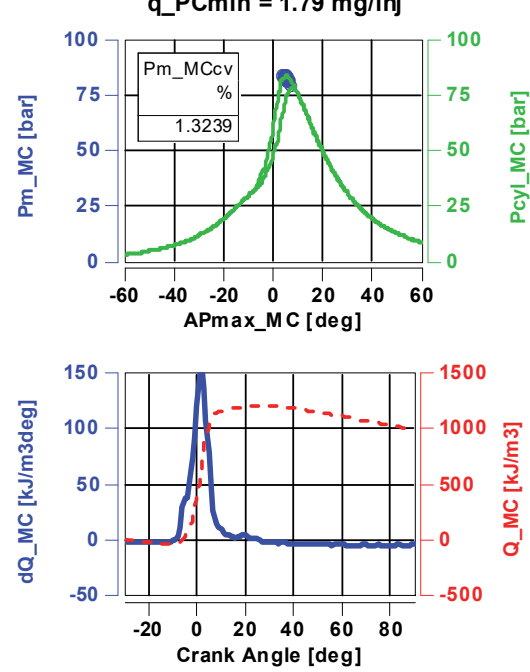

q_PCmin $=2.15 \mathrm{mg} / \mathrm{inj}$
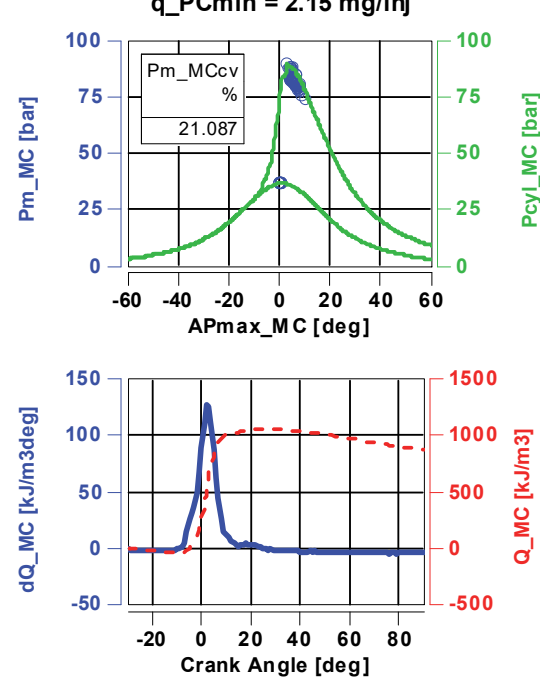

Fig. 6. Analysis of combustion pressure and the heat release rate for large dose injection into the main combustion chamber (qo_MC $=19 \mathrm{mg}$ ). 
Small prechamber injection dose results in high values of $\mathrm{CoV}(\mathrm{Pm} \mathrm{MC})-13 \%$. This is caused by the cylinder misfire, as indicated by the low peak pressure Pm_MC, without any growth characteristic for a combustion process. Increasing the prechamber dose share improves the main combustion process and its uniformity, as evidenced by the small $\mathrm{CoV}$ values $(3.9 \%)$ and large values of the heat release rate (dQ_MC). Increasing the prechamber dose increases the engine operation irregularity. Among the 100 analyzed cycles, a misfire was detected, indicating an excessive fuel dose. Although there are few misfires in this test run, the variation of the peak cylinder pressure value indicates that this process does not take place as intended.

The pressure traces recorded at the injection of various fuel doses into the prechamber and a large main dose (qo $\mathrm{MC}=19 \mathrm{mg} / \mathrm{inj}$ ) indicate improved combustion (Fig. 6). The combustion process irregularity, as determined by $\mathrm{CoV}\left(\mathrm{Pm} \_\mathrm{MC}\right)$, is $1.9 \%$ at the minimum fuel dose for the prechamber. Increasing the dose to a reference value decreases this index (which improves the uniformity of the engine operation) and at the same time increases the rate of combustion. Maximum fuel doses $(2.15 \mathrm{mg} / \mathrm{inj})$ result in more uneven engine performance. A cylinder misfire, resulting in a high $\mathrm{CoV}\left(\mathrm{Pm} \_\mathrm{MC}\right)$ value of $21 \%$, was also observed at this measurement point.

Changes in the heat release rate are an important parameter when analyzing fuel combustion in a combustion system equipped with a prechamber. The heat release rate is lower in the first stage, but later it reaches high values (up to the maximum values). Despite the maximum dose administered to the prechamber, the heat release rate decreases, indicating a too rich fuel mixture obtained in the prechamber, as an excessively lean fuel mixture significantly decreases the rate of combustion.

Comprehensive assessment of the lean gas-air mixtures inflammability limits requires studies to characterize changes in engine operating parameters. The assumption about the lean fuel mixtures combustion has been met because the values of the air excess coefficient change are within the range of 1.3-1.8. Increasing the prechamber dose results in a few percent reduction of the global air excess coefficient (Fig. 7a). The mean values of the maximum cylinder pressure (Pm_av_MC) are constant, apart from the minimum doses injected into the prechamber. This trend is independent of the main fuel dose size (however, the larger the main dose, the smaller the change is) - Fig. $7 \mathrm{~b}$. The maximum pressure increase rate $\left(\mathrm{dP} \mathrm{MC}_{\mathrm{C}}\right)$ in the main chamber indicates the optimum combustion conditions for the small fuel doses fed to the main combustion chamber (Fig. 7c). The optimal doses for the prechamber injection are reduced with the primary dose increase. Also, the upper inflammability limit is determined by the amount of fuel dose injected into the prechamber as the engine load increases. The maximum mean temperatures in the combustion chamber are to a small extent dependent on the size of the fuel dose injected into the prechamber. The dependence of the temperature on the fuel dose is significant at the boundary points where the combustion temperature is significantly reduced. This is partly due to the fact that part of the combustion cycle does not take place, which reduces the mean values of the recorded operating parameters (Fig. 7d).

a)

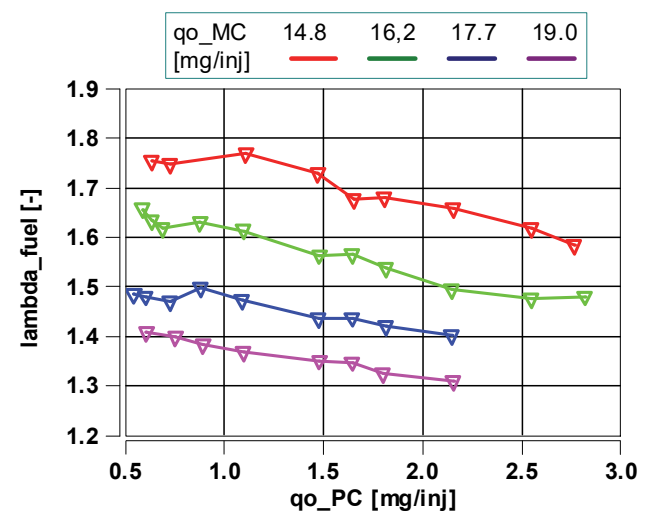

b)

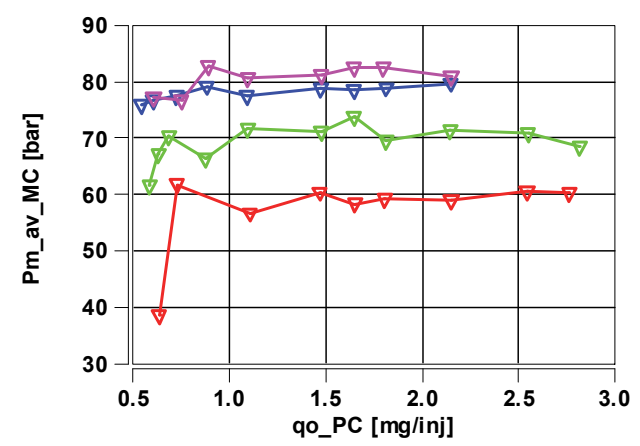

c)

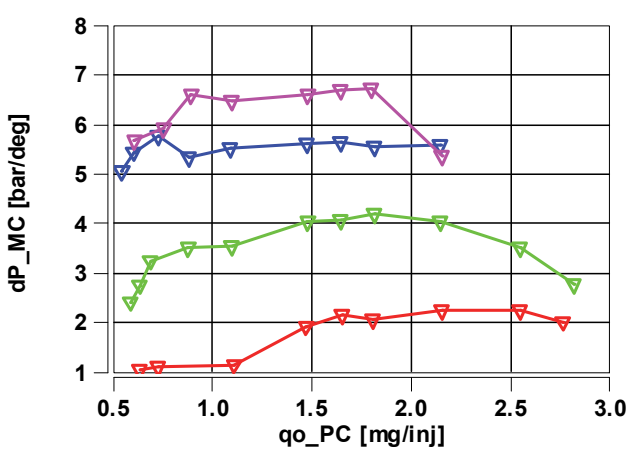

d)

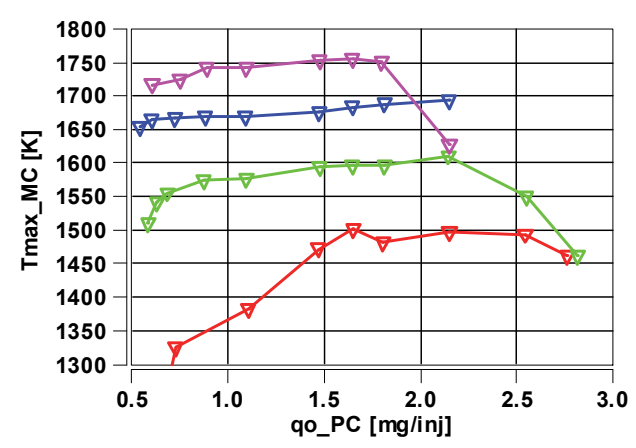

Fig. 7. Analysis of the parameters characterizing the combustion process relative to the prechamber fuel dose: a) air excess coefficient - lambda fuel, b) maximum cylinder pressure - Pm_av_MC, c) maximum cylinder pressure change - dP_MC, d) peak average cylinder temperature - Tmax_MC.

\footnotetext{
* Corresponding author: ireneusz.pielecha@put.poznan.pl
} 
An analysis of the combustion process using the indicated mean effective pressure reveals that its value increases with the increase of the prechamber fuel dose (Fig. 8a). IMEP is rapidly falling in the range of high loads and maximum fuel ratios injected into the prechamber. This means that IMEP can be effectively boosted by increasing the prechamber dose.

A slightly different relationship was obtained in the analysis of the peak cylinder pressure. For this parameter (Fig. 8b), a characteristic minimum was obtained indicating an increase in the fuel combustion rate. This means that in the range of qo $\mathrm{PC}=1.5-2 \mathrm{mg} / \mathrm{inj}$, the first part of the combustion process takes place the quickest since the changes in this value range from 1 to 4 degrees with respect to the minimum doses injected into the prechamber.

a)

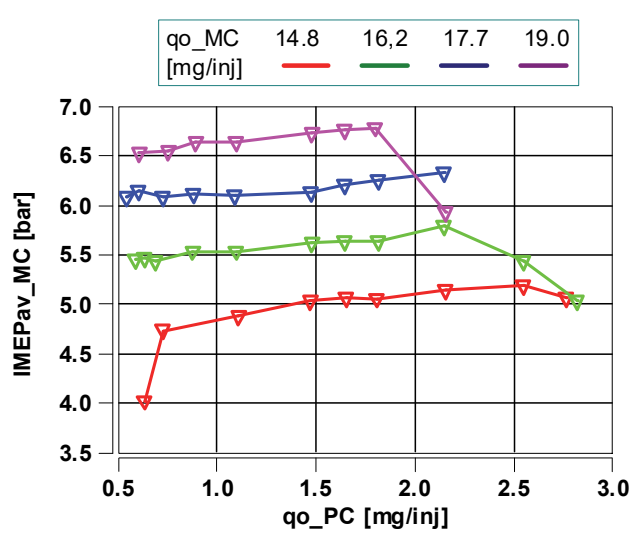

b)

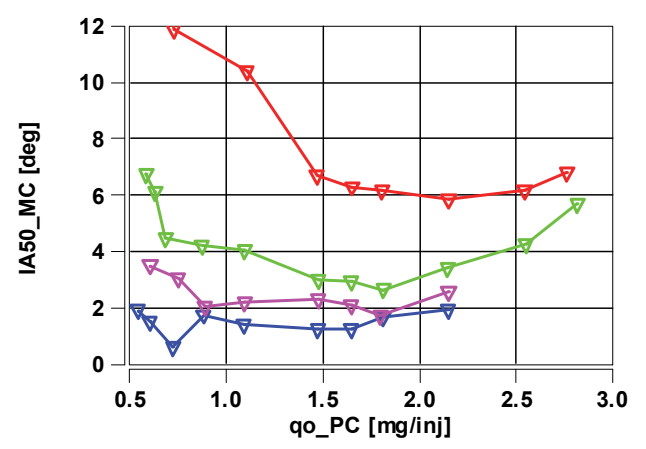

Fig. 8. Combustion process characteristics considering the IMEP values (a) and the IA50_MC (center of combustion) (b), depending on the prechamber $\bar{d}$ ose.

\section{Defining the inflammability limits of fuel mixtures using engine maps}

\subsection{Determination of inflammability limits based on the process thermodynamic indicators}

The parameters characterizing the combustion process obtained in the performed tests allowed to create maps defining the fuel dose inflammability limits based on the analyzed engine operating points in the coordinates qo_PC-qo_MC and the combustion indicators (Fig. 9).

The IMEP characteristics indicates the possibility of obtaining higher values with increasing fuel dose in the main combustion chamber and with no change of its value when altering the prechamber dose size (IMEP MC). A reduction of this value is only observed at small initial doses and a small main dose.

The combustion chamber maximum pressure characteristic (Pm_av_MC) indicates similar relations. However, in this case operating range of high fuel doses injected to both combustion chambers no longer affects the obtained values. The operating area with maximum combustion pressure values is quite large. The pressure changes for low initial fuel doses are minor.

The angle of obtaining $50 \%$ of the released heat value (angle of the peak cylinder pressure IA50_MC) appears to be a good measure for accurately determining the dependence of both fuel doses injected into the combustion chambers. The optimal choice for the initial dose size seems to be 1-2 mg/inj irrelevant of the size of the main dose.

The maximum combustion temperatures (Tmax_MC) are well correlated with the IMEP values since the changes in the contour line of the latter correspond to the changes of the first one.
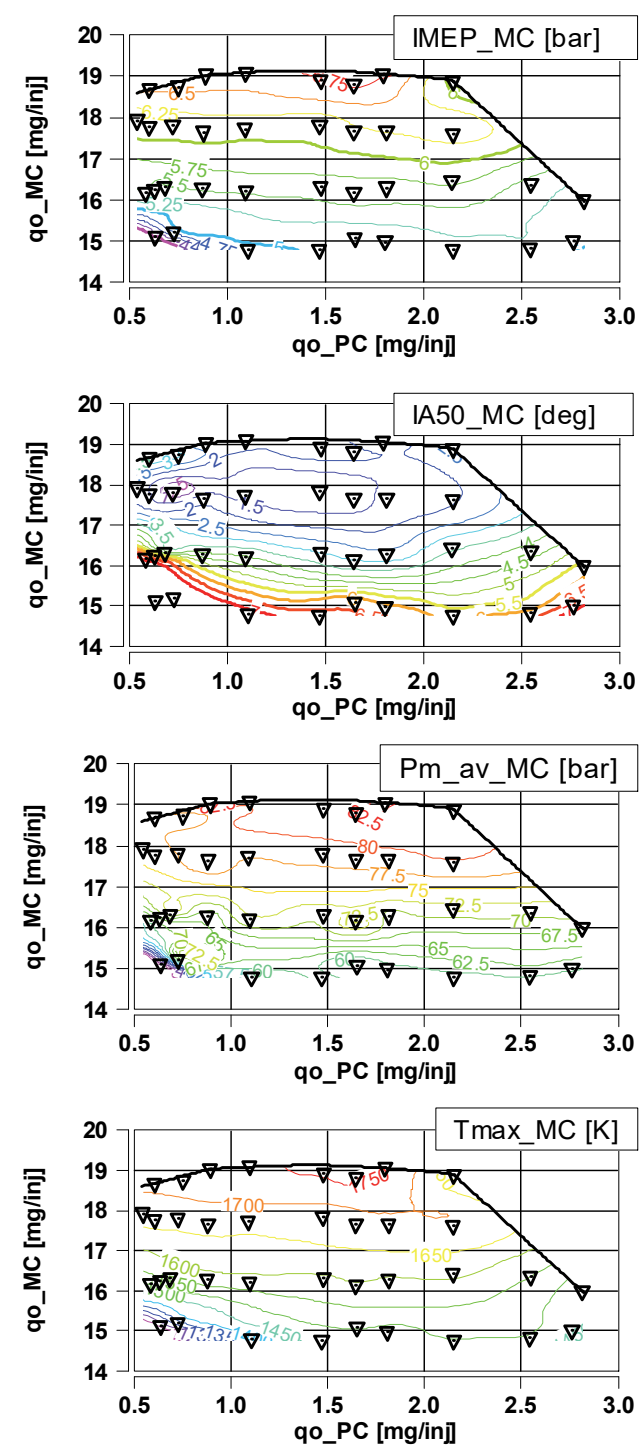

Fig. 9. Combustion indicators maps relative to the dose inflammability characteristics in coordinates qo_PC-qo_MC. 


\subsection{Determination of inflammability limits considering exhaust emissions}

The analysis of the exhaust components emissions allowed determining the dose inflammability maps taking emission of harmful exhaust components into account. Based on the measured $\mathrm{CO}$, THC and $\mathrm{NO}_{\mathrm{x}}$ concentrations, the corresponding unit emissions have been determined relative to the power generated by the engine. Using the AVL Concerto software, envelopes have been generated that characterize the varying degrees of emission reduction during the analysis of each exhaust component. The envelopes obtained for the engine performance indicators were identical (Fig. 9).

Exhaust emissions research during engine operation was carried out without the presence of any exhaust aftertreatment systems. It was found that the reduction of the main fuel dose led to a decrease in nitrogen oxide emissions (Fig. 10). The dose injected into the prechamber has a limited effect on the level of nitrogen oxide emissions. Its effect is noticeable only for small fuel doses in the main combustion chamber.
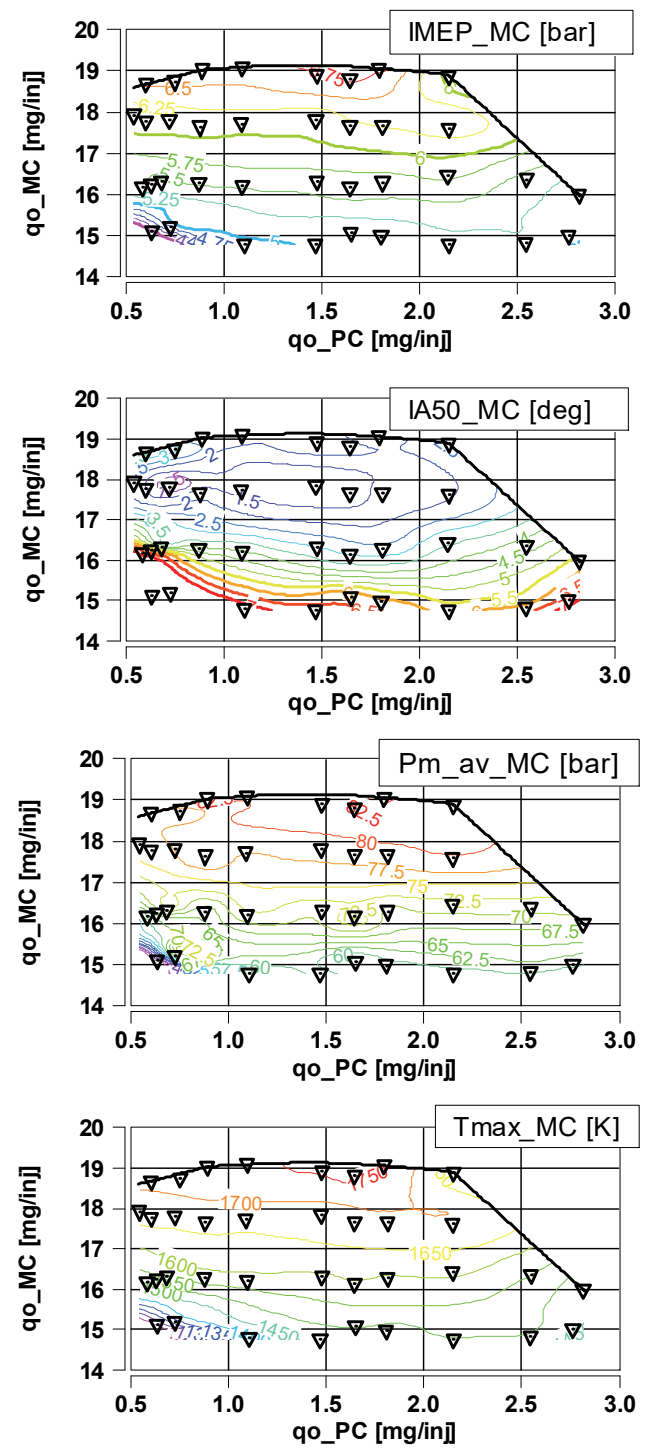

Fig. 10. Exhaust emission characteristics obtained for fuel dose inflammability research.
An emission characteristics of hydrocarbons (including methane) shows a decrease in emissions with the decrease in engine load. This is due to the improvement of the combustion process, but also due to the reduction of the combustion chamber flushing with flue gas that occurs during valve overlap. Highest hydrocarbon emissions occur at the low main dose and at low and high prechamber doses; in that case the emission values are more than double the value obtained for the maximum engine load (19 $\mathrm{mg} / \mathrm{inj})$.

Changes in carbon monoxide emissions are inversely proportional the changes in the initial dose size. For a large part of the created emission characteristics its value does not depend on the main dose. This character is evident at very small prechamber doses. Values below $1 \mathrm{mg} / \mathrm{inj}$ result in high carbon monoxide emissions. This is partly due to a lack of combustion (small initial doses) and partly from the lean mixtures when the conditions for the combustion process are insufficient.

The main result of the conducted research is determining the indicated overall efficiency value as it was determined based on the specific fuel consumption values. A fairly wide range of fuel dose variability was obtained, corresponding to high overall efficiency values. It has been proven that this efficiency decreases as the doses fed into the prechamber drop to minimum at low main doses. A similar tendency was also observed when injecting maximum doses into the prechamber.

\section{Conclusions}

Fuel dose inflammability investigation using a new combustion system, such as a single-fuel gas powered engine equipped with a prechamber and a main chamber, has been carried out. Lean mixtures combustion is possible in such an engine when injecting the minimum fuel doses to the prechamber with a minimum gas share of $3 \%$. Below this value, combustion process irregularities are observed, as evidenced by the high $\mathrm{CoV}$ values (IMEP) exceeding 10\%.

The combustion process research in terms of the fuel dose inflammability leads to the following observations and conclusions:

- the most preferred initial dose inflammability range irrespective of the main dose is observed for doses ranging from 1-2 $\mathrm{mg} / \mathrm{inj}$; in this range $\mathrm{CoV}$ (IMEP) reaches values up to $3 \%$;

- change in the initial dose share in the total fuel dose has little effect on the change in the global air excess coefficient; but despite the small effect on the global value of this indicator, the effects of these changes have a profound impact both on engine performance and on emission factors;

- the peak cylinder pressure - as one of the best indicators for checking the combustion process accuracy - indicates the existence of an initial dose that can be used to accelerate the combustion process: it is a dose in the range $1-2 \mathrm{mg} / \mathrm{inj}$, with smaller values corresponding to higher loads;

- engine performance maps indicate a small effect of the initial dose on the combustion process; the only 
exceptions from this rule are operating points with minimal doses into the prechamber as well as small doses into the main chamber;

- emission characteristics maps confirm the previous conclusions, but the carbon monoxide emissions are the only ones that are clearly dependent on the initial dose size: high engine emission values are observed for engine operation at large initial doses, regardless of the main dose size;

- the overall indicated engine performance contains operating ranges with maximum values that are associated with the initial fuel dose range from 1-2 $\mathrm{mg} / \mathrm{inj}$ and a base fuel dose of 16-19 $\mathrm{mg} / \mathrm{inj}$.

Based on these conclusions, it is not possible to clearly indicate the inflammability limits of the fuel mixture. Incorporating the emission factors and overall engine efficiency allowed to extend the limits of inflammability in a range that was not possible by just using the engine performance indicators (no main dose limits).

The research presented in this paper was performed within the European Research Project Horizon 2020, grant agreement No. 652816, Gas-Only Internal Combustion Engines. This research task was directed by Prof. K. Wislocki, the leader of Research Group. The authors wish to thank the EU for funding the work and express their acknowledgements to all persons, who have had their contribution in this study and the laboratory works.

\section{References}

1. M.I. Khan, T. Yasmin, A. Shakoor, Renewable and Sustainable Energy Reviews 51, 785-797 (2015), DOI: 10.1016/j.rser.2015.06.053

2. M. Noga, B. Sendyka, International Journal of Automotive Technology 15, 1083-1089 (2014), DOI: $10.1007 / \mathrm{s} 12239-014-0112-9$

3. M. Noga, Applied Sciences - Basel 7, 295 (2017), DOI: 10.3390/app7030295

4. Z. Stelmasiak, D. Pietras, IOP Conference SeriesMaterials Science and Engineering 148, UNSP $012087 \quad$ (2016), DOI: 10.1088/1757899X/148/1/012087

5. W. Smuga, L.J. Kapusta, A. Teodorczyk, Journal of Power Technologies 97, 1-6 (2017)

6. R. Pyszczek, L.J. Kapusta, A. Teodorczyk, Journal of Power Technologies 97, 52-60 (2017)

7. M.I. Khan, T. Yasmeen, M.I. Khan, M. Farooq, M. Wakeel, Renewable and Sustainable Energy Reviews 66, 702-741 (2016), DOI: 10.1016/j.rser.2016.08.041

8. T. Korakianitis, A.M. Namasivayam, R.J. Cro-Okes, Progress in Energy and Combustion Science 37, 89112 (2011), DOI: 10.1016/j.pecs.2010.04.002

9. M.M. Tahir, M.S. Ali, M.A. Salim, R.A. Bakar, A.M. Fudhail, M.Z. Hassan, M.S. Abdul Muhaimin, Energy Procedia 68, 355-362 (2015), DOI: 10.1016/j.egypro.2015.03.266
10. C. Bae, J. Kim, Proceedings of the Combustion Institute 36, 3389-3413 (2017), DOI: 10.1016/j.proci.2016.09.009

11. M. Choi, J. Song, S. Park, Fuel 179, 168-178 (2016), DOI: 10.1016/j.fuel.2016.03.099

12. M.A. Kalam, H.H. Masjuki, Energy 36, 3563-3571 (2011)

13. J. Hall, M. Bassett, B. Hibberd, S. Streng, SAE Int. J. Engines 9 (2016)

14. R. Edwards, H. Hass, J. Larive, L. Lonza, H. Maas, D. Rickeard, European Commission Joint Research Centre Institute for Energy and Transport (2014)

15. Z.D. Ristovski, L. Morawska, J. Hitchins, S. Thomas, C. Greenaway, D. Gilbert, Journal of Aerosol Science 31, 403-413 (2000), DOI: 10.1016/S0021-8502(99)00530-3

16. J. Alanen, E. Saukko, K. Lehtoranta, T. Murtonen, H. Timonen, R. Hillamo, P. Karjalai-Nen, H. Kuuluvainen, J. Harra, J. Keskinen, T. Rönkkö, Fuel 162, 155-161 (2015), DOI: 10.1016/j.fuel.2015.09.003

17. W.P. Attard, E. Toulson, A. Huisjen, X. Chen, G. Zhy, H. Schock, SAE Technical Paper 2012-010823 (2012)

18. H. Blaxill, Advanced Fuel and Engine Efficiency Workshop (2017)

19. M. Schumacher, M. Wensing, SAE Technical Paper 2016-01-2176 (2016)

20. D. Assanis, N. Engineer, P. Neuman, M. WoolDridge, SAE Technical Paper 2016-01-2242 (2016)

21. A. Yousefi, M. Birouk, Applied Energy 189, 492505 (2017), DOI: 10.1016/j.apenergy.2016.12.046

22. M.D. Ruter, D.B. Olsen, M.V. Scotto, M.A. Perna, Fuel 91, 298-306 (2012), DOI: 10.1016/j.fuel.2011.06.072

23. D.B. Olsen, J. Adair, B.D. Willson, ASME Internal Combustion Engine Division 2005 Spring Technical Conference (Chicago, 2005)

24. D.B. Olsen, A.T. Kirkpatrick, Journal of Engineering for Gas Turbines and Power 130, 052802-052802-7 (2008)

25. P. Heuser, J. Geiger, S. Lauer, H. Sankhla, G. Ünver, A. Dhongde, World Automotive Congress FISITA (2016)

26. K. Tanoue, T. Kimura, T. Jimoto, J. Hashimoto, Y. Moriyoshi, Applied Thermal Engineering 115, 6471 (2017), DOI: 10.1016/j.applthermaleng.2016.12.079

27. I. Pielecha, W. Cieslik, Journal of Thermal Analysis and Calorimetry 126, 815-827 (2016), DOI: 10.1007/s10973-016-5544-1

28. I. Pielecha, International Journal of Automotive Technology 15, 47-55 (2014), DOI: 10.1007/s12239-014-0005-y

29. I. Pielecha, M. Skowron, W. Bueschke, W. Cieslik, K. Wislocki, IOP Conference Series-Materials 
Science and Engineering 148, UNSP 012081 (2016), DOI: $10.1088 / 1757-899 \mathrm{X} / 148 / 1 / 012081$

30. I. Pielecha, K. Wislocki, P. Borowski, W. Cieslik, Journal of Thermal Analysis and Calorimetry 122, 473-485 (2015), DOI: 10.1007/s10973-015-4735-5

31. I. Pielecha, P. Borowski, J. Czajka, K. Wislocki, J. Kazmierowski, Journal of Thermal Analysis and Calorimetry 119, 695-703 (2015), DOI: 10.1007/s10973-014-4139-y

32. M. Skowron, I. Pielecha, K. Wislocki, IOP Conference Series-Materials Science and Engineering 148, UNSP 012085 (2016), DOI: 10.1088/1757-899X/148/1/012085

33. I. Pielecha, K. Wisłocki, W. Cieślik, P. Borowski, W. Bueschke, M. Skowron, SAE Technical Paper 2016-01-2305 (2016) 